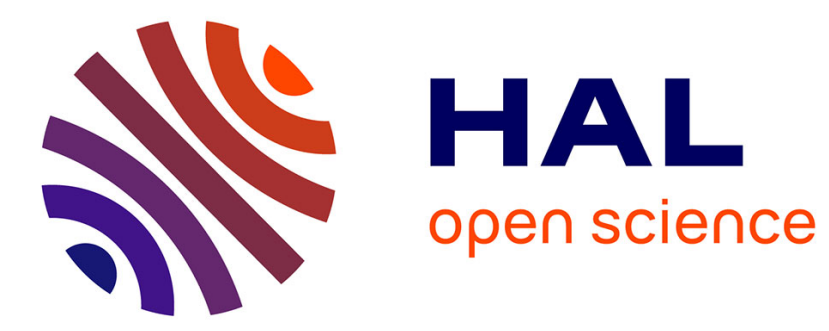

\title{
Identification of minerals from hyperspectral imaging based on a fuzzy logic approach
}

\author{
Ronan Rialland, V. Carrere, Rodolphe Marion, Charles Soussen
}

\section{To cite this version:}

Ronan Rialland, V. Carrere, Rodolphe Marion, Charles Soussen. Identification of minerals from hyperspectral imaging based on a fuzzy logic approach. SPIE Defense + Commercial Sensing, Apr 2021, Online Only, United States. pp.18, 10.1117/12.2587600 . hal-03210707

\section{HAL Id: hal-03210707 \\ https://hal.science/hal-03210707}

Submitted on 28 Apr 2021

HAL is a multi-disciplinary open access archive for the deposit and dissemination of scientific research documents, whether they are published or not. The documents may come from teaching and research institutions in France or abroad, or from public or private research centers.
L'archive ouverte pluridisciplinaire HAL, est destinée au dépôt et à la diffusion de documents scientifiques de niveau recherche, publiés ou non, émanant des établissements d'enseignement et de recherche français ou étrangers, des laboratoires publics ou privés. 


\title{
Identification of minerals from hyperspectral imaging based on a fuzzy logic approach
}

\author{
Ronan Rialland ${ }^{\mathrm{a}}$, Véronique Carrère ${ }^{\mathrm{b}}$, Rodolphe Marion ${ }^{\mathrm{c}}$, and Charles Soussen ${ }^{\mathrm{d}}$ \\ ${ }^{\mathrm{a}, \mathrm{c}} \mathrm{CEA} / \mathrm{DAM} / \mathrm{DIF}$, Arpajon, France

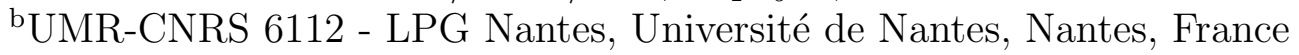 \\ ${ }^{\mathrm{d}}$ L2S, CentraleSupelec - CNRS - Université Paris-Saclay, Gif-sur-Yvette, France
}

\begin{abstract}
We present a fuzzy logic approach allowing the identification of minerals from reflectance spectra acquired by hyperspectral sensors in the VNIR and SWIR ranges. The fuzzy logic system is based on a human reasoning. It compares the positions of the main and secondary absorptions of the unknown spectrum (spectral characteristics estimated beforehand) with those of a reference database (derived from mineralogical knowledge). The proposed solution is first evaluated on laboratory spectra. It is then applied to airborne HySpex and satellite-borne PRISMA images acquired during a dedicated campaign over two quarries in France. This demonstrates the relevance of the method to automatically identify minerals in different mineralogical contexts and in the presence of mixtures.
\end{abstract}

Keywords: Mineral reflectance spectra, Hyperspectral images, HySpex, PRISMA, Identification procedure, Fuzzy logic

\section{INTRODUCTION}

\subsection{Mineralogy and hyperspectral imagery}

Spectroscopy in the solar reflective domain (VNIR (Visible Near-Infrared) [400 - 1300] nm and SWIR (ShortWave InfraRed) $[1300-2500] \mathrm{nm}$ ) is a powerful tool to analyze the physico-chemical properties of minerals. ${ }^{1}$ Indeed, minerals exhibit characteristic spectral features that can be used to identify and characterize them. In particular, the positions of the main and secondary absorptions depend mainly on their chemical composition. Most of the time, a mineral can be identified based on its main absorptions while its secondary absorptions may disappear as a function of physico-chemical properties or in the presence of mixtures with other materials/minerals. Note also that, for minerals belonging to the same mineralogical group, main absorptions can have quite similar position and shape due to their close chemical composition, and secondary absorptions can then be used to discriminate between them. Figure 1 shows reflectance spectra of kaolinite, which exibits narrow and deep absorptions in the SWIR, and of nontronite, which exibits large absorptions in the VNIR and narrow and deep absorptions in the SWIR, from the USGS (US Geological Survey) spectral library. ${ }^{2}$ The overall shape of the reflectance spectrum, also called continuum, changes with surface conditions (e.g. roughness, humidity), so that an identification based on a comparison of a spectrum with an extensive database using a metric generally fails. A solution may then consist in developing a mineral identification procedure based on the positions of the main and secondary absorptions.

Thanks to the development of new airborne and satellite-borne sensors (e.g. Airborne Visible-InfraRed Imaging Spectrometer - Next Generation (AVIRIS-NG), ${ }^{3}$ HySpex sensors, such as Mjölnir (https://www.hyspex . com), "PRecursore IperSpettrale della Missione Applicativa" (PRISMA), ${ }^{4}$ Environmental Mapping and Analysis Program (EnMAP $)^{5}$ ), an increased number of hyperspectral images, where each pixel is a reflectance spectrum, is acquired over large areas of mineralogical interest so that detailed spectral analysis can be performed. Thus, in order to map the physico-chemical properties of the observed surface, an automatic mineral identification procedure is more and more necessary. Moreover, due to the relatively low spatial resolution of the images used

Further author information: (Send correspondence to Ronan Rialland)

Ronan Rialland: E-mail: ronan.rialland@cea.fr, Telephone: +33 (0)16926 6388 


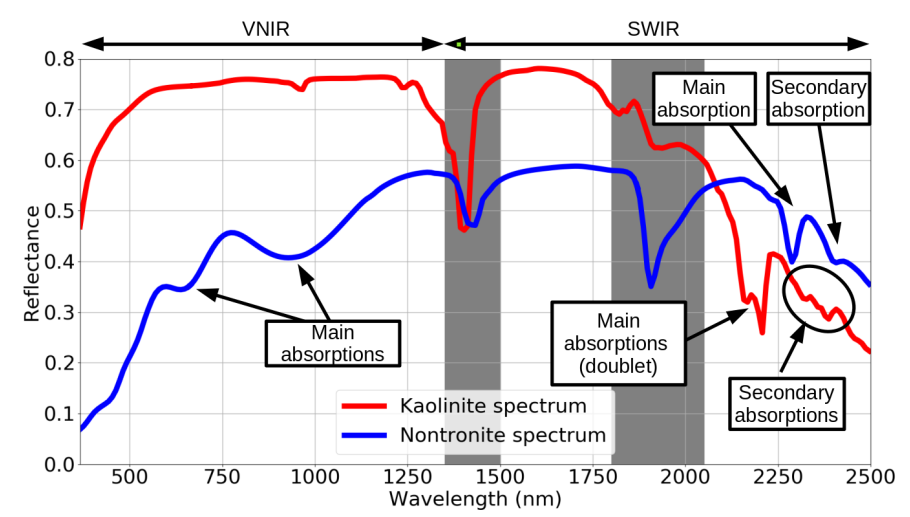

Figure 1: Kaolinite (red) and nontronite (blue) reflectance spectra from USGS spectral library. Spectral masks (grey areas) corresponds to atmospheric water vapor absorption bands and can not be used to identify minerals from airborne or satellite-borne images.

in this study ( $\sim 5 \mathrm{~m}$ for HySpex and $\sim 30 \mathrm{~m}$ for PRISMA), spectral mixtures with other materials/minerals may appear.

In previous studies, ${ }^{6,7,8}$ the authors have developed an automatic deconvolution procedure for mineral reflectance spectra, which estimates the number $N$ of absorptions (main and secondary) and their associated parameters. An absorption is then considered as a modified Gaussian which can be described by four parameters (an amplitude $s$, a position $\mu$, a width $\sigma$ and an asymmetry $k$ ). Also, the procedure computes the uncertainties on the parameters from the noise covariance matrix, either calculated knowing the sensor characteristics or estimated from the data. ${ }^{9}$ Applied to various spectra (synthetic and laboratory data, hyperspectral images), the procedure retrieves the positions of the main and secondary absorptions with errors less than 5 nm, even in noisy cases. $^{8}$

The main objective of this study is to propose an automatic mineral identification procedure based on the estimated positions of the main and secondary absorptions of the unknown spectrum. The procedure has to deal with an unknown number of estimated positions and has to take into account the uncertainties of the deconvolution procedure. Moreover, as main and secondary absorptions do not have the same importance in the identification of a mineral, their respective weights have to be adjusted. Mineral spectral mixtures also have to be handled.

\subsection{Identification based on a human reasoning}

An expert approach, as the one proposed in the GMEX $^{10}$ (Guides for Mineral EXploration) works as follows. The expert first compares the main absorptions of the unknown spectrum to a database in order to identify either the mineral or at least the group to which it belongs. Then, he uses the secondary absorptions to increase the confidence. Three cases can then arise for the expert: 1) only one mineral is unambiguously identified from the spectrum, 2) the spectrum is a mixture of two or more minerals and 3) the spectrum corresponds to several minerals with similar absorptions. A way to compare effectively the positions of an unknown spectrum to the positions of the spectra in the reference database is to use a coincidence measure defined by the expert.

A way to mathematically represent a human reasoning is to use fuzzy logic, a powerful tool introduced in the $1960 \mathrm{~s}^{11}$ to obtain conclusions from vague, ambiguous or impressive data. For any statement, as input of a fuzzy logic system, a degree of truth is defined, named a membership function. Then, a set of If-Then rules are given by an expert or extracted from numerical data. Thus, their first part (i.e. the antecedent) defines the conditions and the second part (i.e. the consequent) defines the corresponding action.

Fuzzy logic has already been applied to mineral reflectance spectra by comparing the full spectrum to a reference library ${ }^{12,13}$ but not in the way we propose here using only the positions of the absorption features. We rely on the work of Perez-Pueyo et al. in Raman spectroscopy where the authors use a two-step procedure 
to identify pigments based on their peak positions in the spectra. ${ }^{14}$ Their solution is composed of two fuzzy logic systems, one for the selection of pigment candidates among a database and one for the computation of an identification score. As output, each selected pigment has an identification score as long as at least one of its peak positions is retrieved. Note that in this solution, main and secondary absorptions have the same weight. Also, an interpretation is necessary to fully analyze the identification score and to handle spectral mixtures.

In the following, we propose a mineral identification procedure based on fuzzy logic. The full procedure is described in section 2 before being validated on synthetic data in section 3 and applied to spectra from hyperspectral images in section 4 .

\section{MINERAL IDENTIFICATION PROCEDURE}

\subsection{Overview}

The procedure is composed of three steps (figure 2). First, the coincidence between the estimated absorption positions $\mu_{e}$ of the unknown spectrum and the positions $\mu_{d}$ of the minerals in the database is evaluated (Coincidence step). It consists in the computation of a similarity degree $S$ and a percentage of matched positions $M_{\text {pos }}$, taking into account the uncertainties on the estimated positions $\sigma_{\mu_{e}}$, for main and secondary absorptions. Then, a fuzzy logic system, based on $S$ and $M_{\text {pos }}$, is designed to identify the mineral, with respect to the database (Identification step). An identification score $I d_{\text {score }}$ is thus obtained for each mineral of the database. Finally, a solution to discriminate between minerals belonging to the same mineralogical group or being part of a mixture, based on $I d_{\text {score }}$, is proposed (Dicrimination step). In the following, we detail these three steps and we describe the database used.

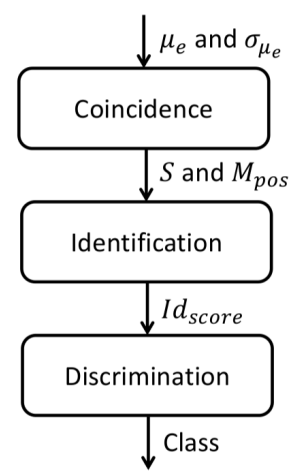

Figure 2: Flowchart of the identification procedure.

\subsection{Coincidence step}

Here, we assess the closeness between the positions $\mu_{e}$ and $\mu_{d}$ by computing a similarity degree $S$ and a percentage of matched positions $M_{\text {pos }}$ for main and secondary absorptions. For this, we define a coincidence function $f$, represented in figure 3. It is a sum of Gaussians, whose centers are $\mu_{e}$ and widths $\sigma_{\mu_{e}}$ (i.e. their respective uncertainties), expressed as:

$$
f(x)=\sum_{i}^{N} \exp \left(\frac{\left(x-\mu_{e_{i}}\right)^{2}}{2 \sigma_{\mu_{e_{i}}}^{2}}\right), \quad \text { if } f(x)>1 \text { then } f(x)=1 .
$$

In the case where two Gaussians are close enough and overlap, the coincidence function maximum is set to 1. Thus, the similarity degree $S \in[0-1]$ is the maximum of $f$, evaluated for each database position $\mu_{d}$. Choosing the maximum operator allows to reproduce the approach of an expert who looks for the absorptions well positioned and does not care, at first, for other absorptions. Other similarity degrees should be used such as the minimum or the mean but they are less effective as they suppose that all the mineral absorption positions are retrieved with a high coincidence value. 


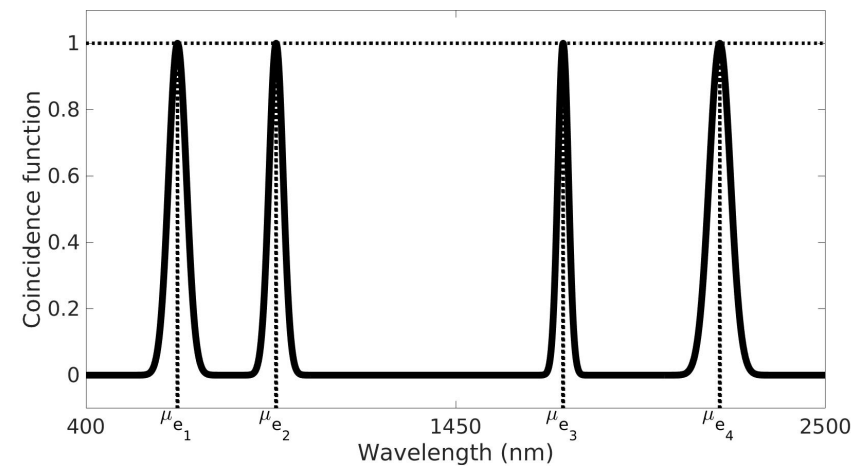

Figure 3: Example of coincidence function with four estimated absorptions. by:

Then, the percentage of matched positions $M_{\text {pos }} \in[0-100] \%$ between $\mu_{e}$ and $\mu_{d}$ is computed as expressed

$$
M_{\text {pos }}=\frac{N_{\mu_{s}}}{N_{\mu_{d}}} * 100
$$

$N_{\mu_{d}}$ is the total number of database positions for a mineral while $N_{\mu_{s}}$ is the number of database positions for a mineral whose coincidence function evaluation is superior to a threshold (here 0.1). The percentage of matched positions is complementary to the similarity degree, which depends only on one position, as it deals with all the database positions.

In the following, we note the similarity degree and the percentage of matched positions for main absorptions with the superscript ${ }^{m}$ and the ones for secondary absorptions with the superscript ${ }^{s}$.

\subsection{Identification step}

Based on the coincidence results, we define a fuzzy logic system (figure 4) to identify the minerals. It reproduces an expert reasoning who searches, among the database, for the minerals corresponding to the coincidence results. Also, it gives a higher weight in the decision to main absorptions than to secondary absorptions.

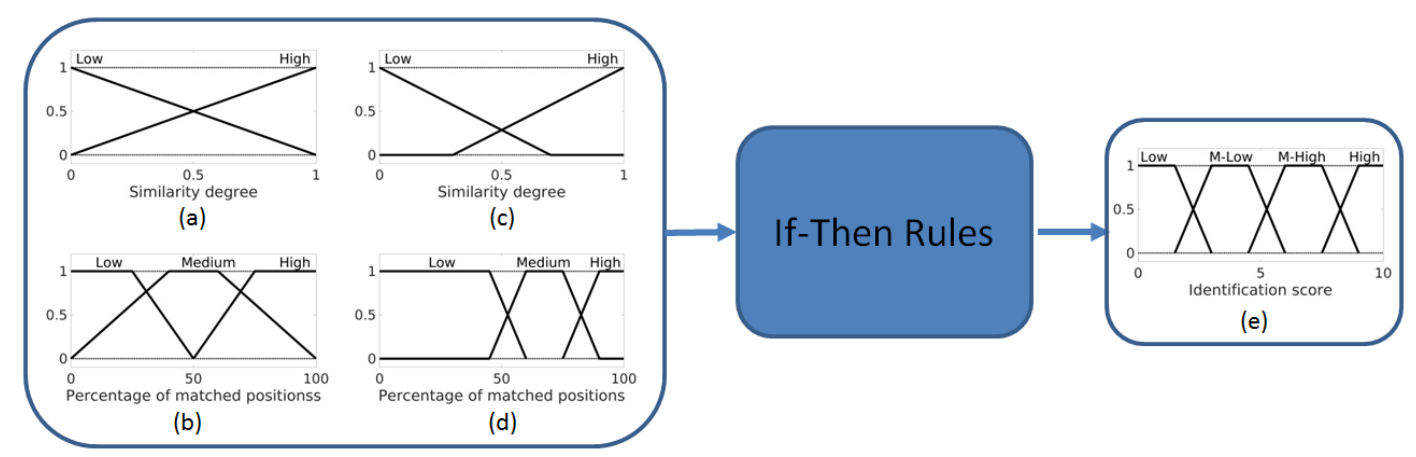

Figure 4: Fuzzy logic system.

The membership functions associated to $S$ and $M_{\text {pos }}$ are represented in figures 4.a and 4.b for main absorptions and in figures 4.c and 4.d for secondary absorptions. The similarity degree is either Low or High and the percentage of matched positions can be Low, Medium or High. As secondary positions are not sufficient to identify a mineral, higher confidence results are necessary to ensure that they correspond to the database secondary positions. It is translated in the fuzzy logic system by a shift of their membership functions.

As output of the fuzzy logic system, we define an identification score $I d_{\text {score }} \in[0-10]$, where 0 is the case of a mineral with $S=0$ and $M_{\text {pos }}=0 \%$ for both main and secondary positions and 10 is the case with $S=1$ 
and $M_{\text {pos }}=100 \%$. Its membership functions, represented in figure 4.e, are Low, Medium Low (noted M-Low), Medium High (noted M-High) and High. They ensure several possibilities of interpretation.

Finally, the set of If-Then rules, defined in table 1, translates the expert reasoning into the fuzzy logic system. It thus gives more importance to main positions than to secondary positions. Thus, if main positions are retrieved with High confidence results, $I d_{\text {score }}$ is High and secondary positions increase the confidence on the result. Then, in the case where only secondary positions are retrieved with High confidence results, $I d_{\text {score }}$ is Low. These rules imply that secondary positions alone are not sufficient to identify a mineral.

Table 1: Set of If-Then rules for minerals with main and secondary absorptions.

\begin{tabular}{|c|c|c|c|c|}
\hline$S^{m}$ & $M_{\text {pos }}^{m}$ & $S^{s}$ & $M_{\text {pos }}^{s}$ & $I d_{\text {score }}$ \\
\hline High & High & High & High / Medium & High \\
\hline High & High & High & Low & Medium High \\
\hline High & High & Low & High / Medium & High \\
\hline High & High & Low & Low & Medium High \\
\hline High & Medium & High & High & High \\
\hline High & Medium & High & Medium / Low & Medium High \\
\hline High & Medium & Low & High & High \\
\hline High & Medium & Low & Medium / Low & Medium High \\
\hline High & Low & High & High / Medium & Medium High \\
\hline High & Low & High & Low & Medium Low \\
\hline High & Low & Low & High / Medium & Medium High \\
\hline High & Low & Low & Low & Medium Low \\
\hline Low & High & High & High & Medium High \\
\hline Low & High & High & Medium / Low & Medium Low \\
\hline Low & High & Low & High & Medium High \\
\hline Low & High & Low & Medium / Low & Medium Low \\
\hline Low & Medium & High & High / Medium & Medium Low \\
\hline Low & Medium & High & Low & Low \\
\hline Low & Medium & Low & High / Medium & Medium Low \\
\hline Low & Medium & Low & Low & Low \\
\hline Low & Low & High & High & Medium Low \\
\hline Low & Low & High & Medium / Low & Low \\
\hline Low & Low & Low & High & Medium Low \\
\hline Low & Low & Low & Medium / Low & Low \\
\hline
\end{tabular}

In some cases, mineral reflectance spectra do not have secondary absorptions and the fuzzy logic system has only two inputs. For these cases, the set of rules is given in table 2.

To solve this fuzzy logic system, we use a Mamdani fuzzy inference system ${ }^{15}$ with the minimum operator as "and method", the product operator as "implication method", the maximum operator as "aggregation method" and the centroid deffuzifer. Note also that a normalization is necessary to obtain an identification score between 0 and 10.

\subsection{Discrimination step}

The discrimination step is applied when several minerals are identified in the unknown spectrum at the previous step. It is a common problem as several minerals can have similar main absorptions or can be part of a spectral mixture. 
Table 2: Set of If-Then rules for minerals without secondary absorptions.

\begin{tabular}{|c|c|c|}
\hline$S^{m}$ & $M_{\text {pos }}^{m}$ & $I d_{\text {score }}$ \\
\hline High & High & High \\
\hline High & Medium & Medium High \\
\hline High & Low & Medium Low \\
\hline Low & High & Medium High \\
\hline Low & Medium & Medium Low \\
\hline Low & Low & Low \\
\hline
\end{tabular}

First of all, all the main absorption positions have to be retrieved to identify the mineral. Thus, minerals with $M_{\text {pos }}<100 \%$ for main absorptions are removed. Then, if only one mineral has a percentage of matched positions equal to $100 \%$, it is unambiguously identified. Finally, when two or more minerals have $M_{\text {pos }}=100 \%$, the spectrum either corresponds to a mixture or to several minerals with similar absorptions. To discriminate between both cases, we compute the maximum distance between the positions of each remaining mineral in the database. If this maximum distance is greater than a threshold (here $10 \mathrm{~nm}$ ), the unknown spectrum is a mixture, otherwise it corresponds to several minerals with similar absorptions.

\subsection{Mineral positions database}

The mineral positions database is a key element of the mineral identification procedure. It is created based on expert knowledge and separates main and secondary absorption positions. The database used in this study is given in table 3 .

Table 3: Mineral positions database.

\begin{tabular}{|c|c|c|}
\hline Mineral - Group & Main absorptions (nm) & Secondary absorptions (nm) \\
\hline Alunite - Sulphate & 1760,2165 & 2324 \\
\hline Buddingtonite - $\mathrm{NH}_{4}$-Mineral & 2013,2112 & $/$ \\
\hline Calcite - Carbonate & 2342 & $/$ \\
\hline Chlorite - Chlorite & $750,928,1130,2248,2340$ & 2140 \\
\hline Dolomite - Carbonate & 2324 & 2356 \\
\hline Gibbsite - Al-hydroxyde & 2268 & 500 \\
\hline Goethite - Fe-hydroxyde & 660,960 & 1538,2215 \\
\hline Gypsum - Sulphate & 1750 & 660 \\
\hline Hematite - Fe-oxyde & 875 & 952,1849 \\
\hline Illite - Mica & $2204,2347,2440$ & $/$ \\
\hline Jarosite - Sulphate & $435,2206,2269$ & $/$ \\
\hline Kaolinite - Phyllosilicate & 2162,2206 & 2378 \\
\hline Montmorillonite - Smectite & 2217 & 2355,2380 \\
\hline Muscovite - Mica & $2204,2342,2435$ & $2135,2175,2466$ \\
\hline Nontronite - Smectite & $660,960,2283$ & \\
\hline Talc - Mg-phyllosilicate & 2288,2390 & \\
\hline
\end{tabular}

The absorption positions given in the database are theoretical values. Thus, depending on the measurement conditions or the physico-chemical properties of the mineral, they may vary slightly (no more than $20 \mathrm{~nm}$ for tested SWIR absorptions). These variations are included in the uncertainties on the estimated positions $\sigma_{\mu_{e}}$ to be taken into account in the coincidence step. 


\section{VALIDATION ON SYNTHETIC DATA}

\subsection{Synthetic data description}

The proposed mineral identification procedure is validated on three unknown spectra whose positions are given in table 4. The total uncertainty on the positions is set to $\sigma_{\mu_{e}}=5 \mathrm{~nm}$. Each spectrum corresponds to a specific case to discriminate (unique mineral, mineral mixture and minerals with similar absorptions). Spectrum 1 corresponds to an unique mineral, montmorillonite. Its three absorptions correspond to the montmorillonite main absorption and to two out of three kaolinite secondary absorptions. Other minerals can be retrieved but without all their main absorptions. The absorption positions for unknown spectrum 2 were selected to correspond to a mixture of alunite and kaolinite, where kaolinite positions are fixed at their exact values in the database. Also, alunite secondary absorption is not present. Absorptions of spectrum 3 correspond to muscovite main absorptions. However, illite, a mineral belonging to the same mineralogical group as muscovite, exhibits the same absorptions but slightly shifted. The mineral identification procedure has then to identify the unknown spectrum between muscovite and illite.

Table 4: Synthetic absorption positions of three spectra used for the validation.

\begin{tabular}{|c|c|}
\hline Case & $\mu_{e}(\mathrm{~nm})$ \\
\hline spectrum 1 & $2212,2310,2380$ \\
\hline spectrum 2 & $1760,2162,2206,2312,2380$ \\
\hline spectrum 3 & $2204,2342,2435$ \\
\hline
\end{tabular}

\subsection{Montmorillonite identification}

Results for spectrum 1 are summarized in table 5. First of all, as montmorillonite is the only mineral to have $M_{\text {pos }}^{m}=100 \%$ for main absorptions, it is identified with $I d_{\text {score }}=8.23$. We notice that its main absorption is retrieved with a similarity degree of 0.61 as the position at $2212 \mathrm{~nm}$ of the unknown spectrum is shifted from the montmorillonite database position at $2217 \mathrm{~nm}$. Then, kaolinite and nontronite secondary absorption positions are all retrieved with a high similarity degree (0.96) but their identification scores are relatively small (5.61 for kaolinite and 3.27 for nontronite) as their main absorptions are not retrieved. Finally, a part of the absorptions of gypsum, illite, jarosite muscovite and talc are also retrieved.

Table 5: Mineral identification procedure results for spectrum 1.

\begin{tabular}{|c|c|c|c|c|}
\hline Mineral & $S^{m} / M_{\text {pos }}^{m}$ & $S^{s} / M_{\text {pos }}^{s}$ & $I d_{\text {score }}$ & Class \\
\hline Gypsum & $0 / 0$ & $0.83 / 50$ & 0.09 & Not identified \\
\hline Illite & $0.28 / 33$ & - & 3.07 & Not identified \\
\hline Jarosite & $0.49 / 33$ & $0 / 0$ & 3.91 & Not identified \\
\hline Kaolinite & $0.49 / 50$ & $0.96 / 66$ & 5.61 & Not identified \\
\hline Montmorillonite & $0.61 / 100$ & - & 8.23 & Identified \\
\hline Muscovite & $0.28 / 33$ & - & 3.07 & Not identified \\
\hline Nontronite & $0 / 0$ & $0.96 / 100$ & 3.27 & Not identified \\
\hline Talc & $0.14 / 50$ & $0 / 0$ & 1.58 & Not identified \\
\hline
\end{tabular}

\subsection{Alunite-kaolinite mixture}

Results for spectrum 2 are summarized in table 6. Spectrum 2 is here identified as a mixture of three minerals: alunite, gypsum and kaolinite, as $M_{\text {pos }}^{m}=100 \%$ for their main absorption positions. The main absorptions of gypsum, which belongs to the same mineralogical group as alunite, is retrieved but shifted $\left(S^{m}=0.14\right)$ and its 
secondary absorptions are partially retrieved. Thus, gypsum is identified as part of the mixture but its $I d_{s c o r e}$ is relatively small $\left(I d_{\text {score }}=4.26\right)$. Then, alunite main absorptions are retrieved with a high similarity degree (0.92) but not its secondary absorptions. Thus, its $I d_{\text {score }}$ is lower than the one of kaolinite for which main and secondary absorptions are all retrieved at their exact positions in the database. In this case, we retrieved the alunite-kaolinite mixture with a strong predominance (from an $I d_{\text {score }}$ point of view) of kaolinite and the possibility of a minor contribution of gypsum.

Table 6: Mineral identification procedure results for spectrum 2.

\begin{tabular}{|c|c|c|c|c|}
\hline Mineral & $S^{m} / M_{\text {pos }}^{m}$ & $S^{s} / M_{\text {pos }}^{s}$ & $I d_{\text {score }}$ & Class \\
\hline Alunite & $0.92 / 100$ & $0 / 0$ & 6.68 & Mixture \\
\hline Calcite & $0 / 0$ & $0.49 / 100$ & 3.28 & Not identified \\
\hline Gypsum & $0.14 / 100$ & $0.19 / 50$ & 4.26 & Mixture \\
\hline Illite & $0.92 / 33$ & - & 5.16 & Not identified \\
\hline Jarosite & $1 / 33$ & $0 / 0$ & 5.31 & Not identified \\
\hline Kaolinite & $1 / 100$ & $1 / 100$ & 10 & Mixture \\
\hline Muscovite & $0.92 / 33$ & - & 5.16 & Not identified \\
\hline Nontronite & $0 / 0$ & $0.96 / 100$ & 3.28 & Not identified \\
\hline Talc & $0.14 / 50$ & $0 / 0$ & 1.58 & Not identified \\
\hline
\end{tabular}

\subsection{Illite-muscovite discrimination}

Results for spectrum 3 are summarized in table 7 . Three minerals have a percentage of matched positions equal to $100 \%$ : calcite, illite and muscovite. However, the positions of their main absorptions in the database are close and we identify the mineral with the higher $I d_{\text {score }}$. Thus, muscovite is identified as its $I d_{\text {score }}$ is equal to 10 .

The case of calcite is particular as it has an unique main absorption position at $2342 \mathrm{~nm}$ which is close to positions of other minerals. This example emphasizes the importance of sorting main and secondary absorptions correctly from the start while building the reference database. Thus, false identification of calcite, as well as montmorillonite and other minerals with an unique main absorption, is possible. To avoid this risk of false identification, a first solution is to use expert knowledge based on the geological mineralogical context. Another solution can be to include other absorptions parameters (i.e. amplitude, width and asymmetry) to improve the identification score.

Table 7: Mineral identification procedure results for spectrum 3.

\begin{tabular}{|c|c|c|c|c|}
\hline Mineral & $S^{m} / M_{\text {pos }}^{m}$ & $S^{s} / M_{\text {pos }}^{s}$ & $I d_{\text {score }}$ & Class \\
\hline Calcite & $0.99 / 100$ & $0 / 0$ & 7.06 & Similar absorptions \\
\hline Chlorite & $0.92 / 20$ & $0 / 0$ & 4.59 & Not identified \\
\hline Illite & $0.74 / 100$ & - & 8.67 & Similar absorptions \\
\hline Jarosite & $0.92 / 33$ & $0 / 0$ & 5.16 & Not identified \\
\hline Kaolinite & $0.92 / 50$ & $0 / 0$ & 6.56 & Not identified \\
\hline Muscovite & $1 / 100$ & - & 10 & Similar absorptions \\
\hline
\end{tabular}

\section{APPLICATION TO AIRBORNE AND SATELLITE-BORNE IMAGES}

\subsection{Data description}

The procedure is applied to airborne HySpex and satellite-borne PRISMA images acquired during a dedicated campaign over two quarries in France (figure 5). Three minerals of interest can be observed: gypsum, calcite 
(Cherves-Richemont) and kaolinite (Chevanceaux). They are used in the production of plasterboard or as aggregates (Cherves-Richemont) and refractory ceramics (Chevanceaux). HySpex images were acquired in September 2019, with a $0.5 \mathrm{~m}$ and a $1.0 \mathrm{~m}$ spatial resolution for the VNIR and SWIR respectively. The number of bands were respectively 160 and 162 for the VNIR and SWIR with a $\sim 4 \mathrm{~nm}$ and $\sim 7 \mathrm{~nm}$ spectral resolution. In this study, only SWIR images are used. Images were atmospherically corrected using ATCOR4. ${ }^{16}$ To improve the signal-to-noise ratio, reflectance images were spatially downsampled to $5 \mathrm{~m}$. PRISMA image, only available on Chevanceaux, were acquired in September 2020, with a $30 \mathrm{~m}$ spatial resolution. There are 234 bands with a spectral resolution of $\sim 10 \mathrm{~nm}$. The image was atmospherically corrected using ATCOR2/3. ${ }^{16}$ Samples were collected at the time of HySpex image acquisition in order to create a spectral database gathering the various spectral signatures observed in the quarries. An ASD FieldSpec®FR3 was used to this end for the laboratory measurements.

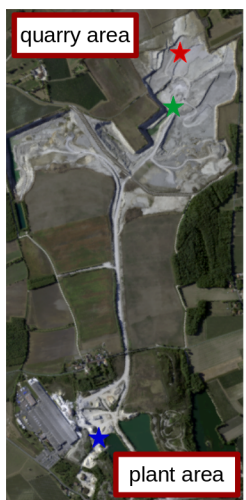

(a)

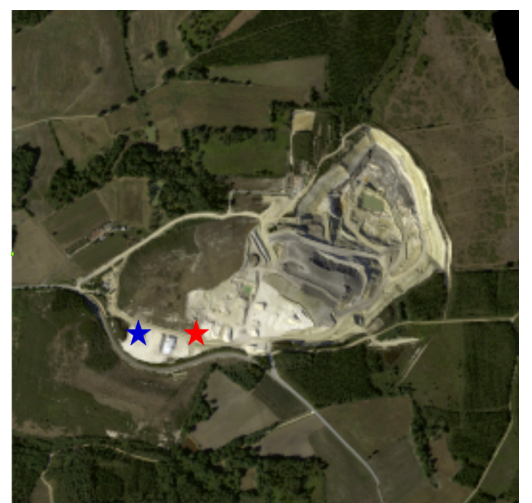

(b)

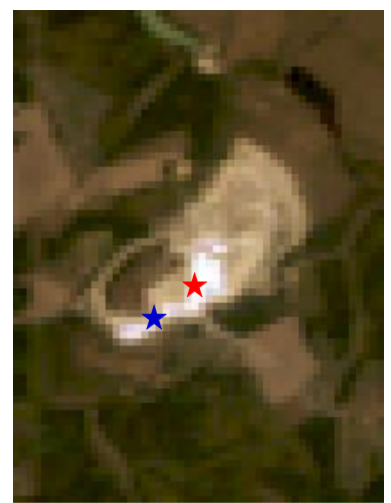

(c)

Figure 5: HySpex image (a) acquired over the Cherves-Richemont quarry. HySpex (b) and PRISMA (c) images acquired over the Chevanceaux quarry. The stars indicate the positions in the images of the spectra used in this study.

In the following, a deconvolution procedure ${ }^{8}$ was applied to spectra selected from the images in order to estimate their absorption positions. The noise covariance was estimated using HYSIME. ${ }^{9}$

The proposed mineral identification procedure is applied to a gyspum-calcite mixture for Cherves-Richemont and results for kaolinite on HySpex and PRISMA images are compared for Chevanceaux.

\subsection{Gypsum and calcite spectral mixture}

On the Cherves-Richemont HySpex image, gypsum and calcite are the two predominant observable minerals. As a reminder, gypsum (in red in figure 6) exhibits one main absorption at $1750 \mathrm{~nm}$ and two secondary absorptions at 1538 and $2215 \mathrm{~nm}$ whereas calcite (in blue in figure 6) exhibits one main absorption at $2342 \mathrm{~nm}$ and one secondary absorption at $2156 \mathrm{~nm}$. However, near the roads and the plant area, gypsum and calcite can be mixed. The resulting spectrum (in green in figure 6) exhibits the main absorptions of both minerals.

Results are given in table 8 for the three spectra. First, gypsum spectrum is classified as a mixture of gypsum and montmorillonite. Here, the identification of montmorillonite is not relevant as its unique main absorption is close to the gypsum secondary absorption at $2215 \mathrm{~nm}$. Then, calcite spectrum is classified as a mixture of calcite and dolomite with $I d_{\text {score }}$ slightly higher for calcite. Indeed, the absorptions of calcite and dolomite are close as they belong to the same mineralogical group and the estimated positions at $2333 \mathrm{~nm}$ is between their main positions. Finally, for the mixture spectrum, five minerals are identified: alunite, calcite, dolomite, gypsum and montmorillonite. The presence of alunite is due to an overestimation of the number of absorptions in the deconvolution procedure while dolomite and montmorillonite were already present for "pure" gypsum and calcite spectra. Finally, the spectrum is identified as a gypsum-calcite mixture. A possible solution to avoid the false identification of montmorillonite, dolomite and alunite could be to use the other absorption parameters (i.e. 


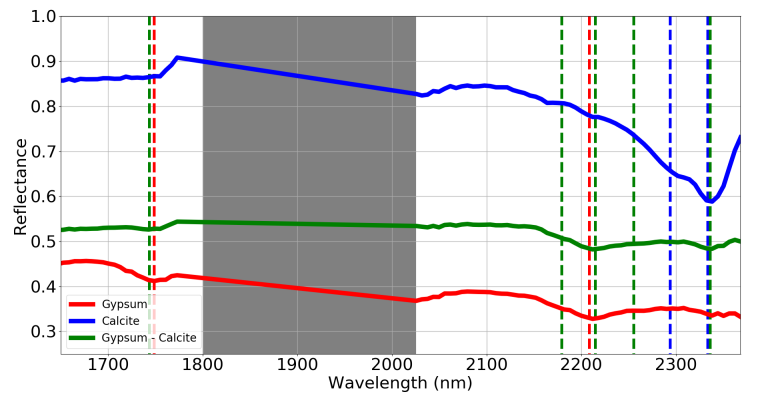

Figure 6: Gypsum (red), calcite (blue) and gypsum-calcite mixture (green) from HySpex image over ChervesRichemont. Estimated positions are represented as vertical dashed lines with the corresponding colors.

amplitude, width and asymmetry) to improve the mineral identification procedure by giving more informations on the unknown spectrum.

Table 8: Results of the mineral identification procedure for the three selected spectra.

\begin{tabular}{|c|c|c|c|}
\hline Mineral & Gypsum & Calcite & Gypsum - Calcite mixture \\
\hline- & $I d_{\text {score }} /$ Class & $I d_{\text {score }} /$ Class & $I d_{\text {score }} /$ Class \\
\hline Alunite & $3.56 /$ Not identified & $3.28 /$ Not identified & $7.44 /$ Mixture \\
\hline Calcite & & $5.35 /$ Mixture & $6.03 /$ Mixture \\
\hline Dolomite & & $5.33 /$ Mixture & $4.70 /$ Mixture \\
\hline Gypsum & $7.72 /$ Mixture & & $6.76 /$ Mixture \\
\hline Montmorillonite & $8.25 /$ Mixture & & $9.77 /$ Mixture \\
\hline
\end{tabular}

\subsection{Kaolinite identification on HySpex and PRISMA images}

As a reminder, kaolinite has two main absorptions at 2162 and $2206 \mathrm{~nm}$, the doublet, and three secondary absorptions at 2312, 2355 and $2380 \mathrm{~nm}$. Note that for HySpex images, the absorption at $2380 \mathrm{~nm}$ is out of the spectral range of the sensor. Four spectra are selected, two from the HySpex image and two from the PRISMA image (figure 7). For each, kaolinite is easily identifiable based on its doublet but secondary absorptions are not distinguishable for the PRISMA image. Note also, the presence of a very weak absorption at $2260 \mathrm{~nm}$, probably due to the presence of gibbsite (it is retrieved with PRISMA but the signal is very close to the noise level).

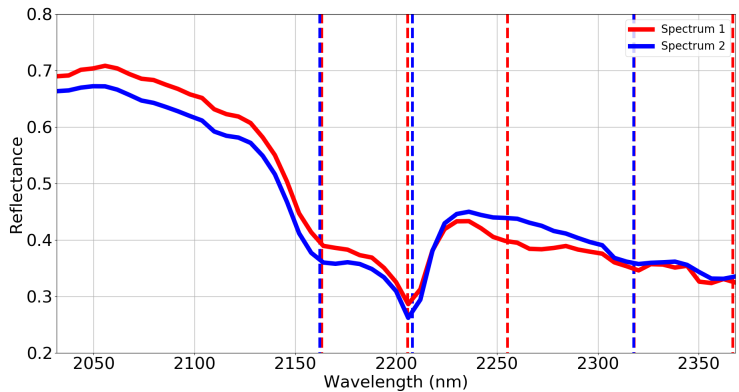

(a)

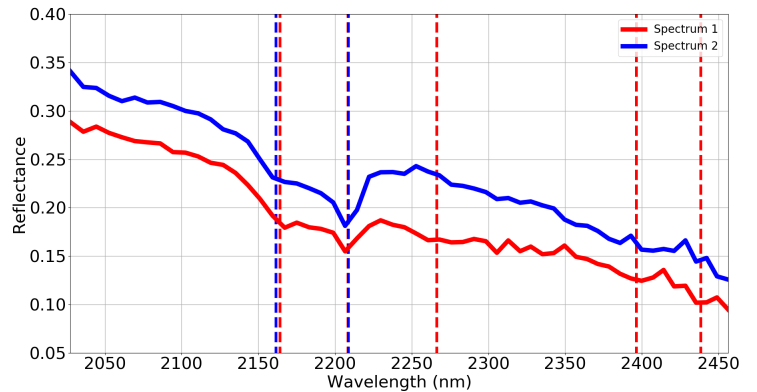

(b)

Figure 7: Kaolinite spectra from (a) Hyspex and (b) PRISMA images. Estimated positions are represented as vertical dashed lines with the corresponding colors. 
Results are given in table 9 for the four spectra. First of all, the presence of montmorillonite is not relevant but can be explained by the fact that its unique main position is close to the kaolinite position at $2206 \mathrm{~nm}$. Likewise, for HySpex spectra, the unique main position of dolomite is close to the kaolinite secondary position at $2317 \mathrm{~nm}$. Nontronite is also identified in spectrum 1 from PRISMA image as its unique main position in the SWIR is close to the gibbsite position at $2260 \mathrm{~nm}$. Then, kaolinite is retrieved for the four selected spectra with an $I d_{\text {score }}$ higher for HySpex than for PRISMA as secondary positions were not estimated for PRISMA. Moreover, gibbsite is identified in two spectra as expected. Finally, as said previously, the "false" identification of dolomite, montmorillonite and nontronite could be probably avoided by including other absorption parameters in the identification procedure.

Table 9: Results of the mineral identification procedure for the four selected spectra.

\begin{tabular}{|c|c|c|c|c|}
\hline Mineral & Hyspex - spectrum 1 & Hyspex - spectrum 2 & PRISMA - spectrum 1 & PRISMA - spectrum 2 \\
\hline- & $I d_{\text {score }} /$ Class & $I d_{\text {score }} /$ Class & $I d_{\text {score }} /$ Class & $I d_{\text {score }} /$ Class \\
\hline Dolomite & $6.10 /$ Mixture & $6.05 /$ Mixture & & \\
\hline Gibbsite & $4.53 /$ Mixture & $3.27 /$ Not identified & $6.94 /$ Mixture & $6.83 /$ Mixture \\
\hline Kaolinite & $7.76 /$ Mixture & $9.80 /$ Mixture & $7.59 /$ Mixture & $8.51 /$ Mixture \\
\hline Montmorillionite & $7.71 /$ Mixture & $8.11 /$ Mixture & $8.21 /$ Mixture & \\
\hline Nontronite & & $3.27 /$ Not identified & $7.24 /$ Mixture & \\
\hline
\end{tabular}

\section{CONCLUSION}

In this study, we have presented a mineral identification procedure based on fuzzy logic and relying on a comparison with absorption positions from a reference database. The procedure computes an identification score for each mineral, based on the main and secondary absorption positions, and takes into account uncertainties. Then, a discrimination strategy is proposed to identify if the unknown spectrum corresponds to a mineral mixture or to minerals with similar main absorptions. Several cases have been evaluated (synthetic data, hyperspectral images) to validate and test its performances.

Several improvements should be considered at this stage. First, minerals with an unique main absorption need to be handled differently as they may create false identifications. To this end, other absorption parameters, such as width, amplitude and asymmetry, could be used to increase the information contained in the coincidence results and to improve the confidence on the identification score. Finally, similar procedures could be developed to characterize physico-chemical properties of minerals.

\section{REFERENCES}

[1] Clark, R. N., [Manual of remote sensing, volume 3, remote sensing for the Earth sciences], ch. 1: Spectroscopy of rocks and minerals, and principles of spectroscopy, 3-58, John Wiley and Sons, New York (1999).

[2] Kokaly, R., Clark, R. N., Swayze, G., Livo, K. E., Hoefen, T., Pearson, N., Wise, R., Benzel, W., Lowers, H., and Driscoll, R. L., "USGS Spectral Library Version 7," report, U.S. Geological Survey (Apr. 2017).

[3] Hamlin, L., Green, R. O., Mouroulis, P., Eastwood, M., Wilson, D., Dudik, M., and Paine, C., "Imaging spectrometer science measurements for terrestrial ecology: AVIRIS and new developments," in [2011 Aerospace Conference], 1-7 (March 2011).

[4] Loizzo, R., Guarini, R., Longo, F., Scopa, T., Formaro, R., Facchinetti, C., and Varacalli, G., "Prisma: The Italian hyperspectral mission," in [IGARSS 2018 - 2018 IEEE International Geoscience and Remote Sensing Symposium], 175-178 (July 2018).

[5] Guanter, L., Kaufmann, H., Segl, K., Foerster, S., Rogass, C., Chabrillat, S., Kuester, T., Hollstein, A., Rossner, G., Chlebek, C., Straif, C., Fischer, S., Schrader, S., Storch, T., Heiden, U., Mueller, A., Bachmann, M., Mühle, H., Müller, R., Habermeyer, M., Ohndorf, A., Hill, J., Buddenbaum, H., Hostert, P., Van der 
Linden, S., Leitao, P. J., Rabe, A., Doerffer, R., Krasemann, H., Xi, H., Mauser, W., Hank, T., Locherer, M., Rast, M., Staenz, K., and Sang, B., "The EnMAP spaceborne imaging spectroscopy mission for Earth observation," Remote Sensing 7(7), 8830-8857 (2015).

[6] Brossard, M., Marion, R., and Carrère, V., "Deconvolution of SWIR reflectance spectra for automatic mineral identification in hyperspectral imaging," Remote Sensing Letters 7(6), 581-590 (2016).

[7] Marion, R. and Carrère, V., "Mineral mapping using the Automatized Gaussian Model (AGM) - Application to two industrial French sites at Gardanne and Thann," Remote Sensing 10(1) (2018).

[8] Rialland, R., Soussen, C., Marion, R., and Carrère, V., "Improved deconvolution of mineral reflectance spectra," IEEE Journal of Selected Topics in Applied Earth Observations and Remote Sensing (2021).

[9] Bioucas-Dias, J. M. and Nascimento, J. M. P., "Hyperspectral subspace identification," IEEE Transactions on Geoscience and Remote Sensing 46, 2435-2445 (Aug 2008).

[10] Pontual, S., Merry, N., and Gamson, P., "GMEX: Guides for Mineral EXploration: Spectral interpretation field manual," AusSpec International Ltd.: Queenstown, New Zealand 1, 191 (2010).

[11] Zadeh, L., "Fuzzy sets," Information and Control 8(3), 338-353 (1965).

[12] Asadzadeh, S. and de Souza Filho, C. R., "A review on spectral processing methods for geological remote sensing," International Journal of Applied Earth Observation and Geoinformation 47, 69 - 90 (2016).

[13] Livo, K. E. and Clark, R. N., "The tetracorder user guide: version 4.4," tech. rep., Reston, VA (2014).

[14] Perez-Pueyo, R., Soneira, M. J., Castanys, M., and Ruiz-Moreno, S., "Fuzzy approach for identifying artistic pigments with raman spectroscopy," Applied Spectroscopy 63(8), 947-957 (2009).

[15] Mamdani, E. and Assilian, S., "An experiment in linguistic synthesis with a fuzzy logic controller," International Journal of Man-Machine Studies 7(1), 1-13 (1975).

[16] Richter, R. and Schlapfer, D., "Atmospheric/topographic correction for airborne imagery: ATCOR-4 user Guide," DLR IB , 565-02 (2012). 